\title{
No limit in interspecific hybridization in schistosomes: observation from a case report
}

\author{
Jérôme Depaquit $^{1,2, *}$, Mohammad Akhoundi ${ }^{3}$, Djamel Haouchine ${ }^{3}$, Stéphane Mantelet ${ }^{3}$, and Arezki Izri ${ }^{3,4}$ \\ ${ }^{1}$ EA7510 ESCAPE, USC ANSES “VECPAR”, UFR Pharmacie, Université de Reims Champagne-Ardenne, France \\ ${ }^{2}$ Laboratoire de Parasitologie-Mycologie, Hôpital Maison Blanche, Reims, France \\ ${ }^{3}$ Département de Parasitologie-Mycologie, Hôpital Avicenne AP-HP, Bobigny, France \\ ${ }^{4}$ Unité des Virus Emergents (Université Aix-Marseille- IRD 190 - Inserm 1207 - IHU Méditerranée infection), Marseille, France
}

Received 10 November 2018, Accepted 18 February 2019, Published online 1 March 2019

\begin{abstract}
Schistosomiasis is one of the most significant parasitic diseases of humans. The hybridization of closely related Schistosoma species has already been documented. However, hybridization between phylogenetically distant species is unusual. In the present study, we characterized the causative agent of schistosomiasis in a 14-year-old patient with hematuria from Côte d'Ivoire, using morphological and molecular approaches. A 24-hour parasitological examination of urine showed the presence of numerous eggs $(150 \mu \mathrm{m}$ long $\times 62 \mu \mathrm{m}$ wide) with a lateral spine $(25 \mu \mathrm{m})$, identified morphologically as Schistosoma mansoni. Examination of stools performed on the same day found no parasites. The urine and stool examinations of the patient's family members performed two weeks later showed neither parasites nor hematuria; but in contrast, many S. mansoni eggs were found again in the patient's urine, but never in his stools. Conventional PCRs were performed, using two primer pairs targeting 28S-rDNA and COI mtDNA. The 28S-rDNA sequence of these eggs, compared with two reference sequences from GenBank demonstrated a hybrid with 25 double peaks, indicating clearly hybrid positions (5.37\%) between $S$. mansoni and S. haematobium. Similarly, we identified a unique $S$. mansoni COI sequence for the two eggs, with $99.1 \%$ homology with the $S$. mansoni reference sequence. Consequently, this case was the result of hybridization between an S. haematobium male and an S. mansoni female. This should be taken into consideration to explore the elimination of ectopic schistosome eggs in the future.
\end{abstract}

Key words: Schistosoma mansoni, S. haematobium, Hematuria, Hybrid, phylogenetic distance.

Résumé - Pas de limites dans l'hybridation entre schistosomes : réflexions à propos d'un cas clinique. La schistosomiase est l'une des maladies parasitaires les plus importantes chez l'Homme. L'hybridation d'espèces de Schistosoma très apparentées a déjà été documentée. Cependant, l'hybridation entre espèces phylogénétiquement éloignées est inhabituelle. Dans le cas que nous rapportons, nous avons caractérisé l'agent responsable d'une bilharziose urinaire chez un patient de 14 ans originaire de Côte d'Ivoire à l'aide d'approches morphologiques et moléculaires. Un examen parasitologique effectué sur des urines de 24 heures a révélé la présence de nombreux œufs $(150 \mu \mathrm{m}$ de long $\times 62 \mu \mathrm{m}$ de large) à éperon latéral $(25 \mu \mathrm{m})$, identifiés morphologiquement comme appartenant à l'espèce Schistosoma mansoni. L'examen parasitologique des selles effectué le même jour n'a révélé aucun parasite. Les examens d'urines et de selles des membres de sa famille effectués deux semaines plus tard ne montraient aucun parasite ni hématurie, mais en revanche, de nombreux œufs de $S$. mansoni ont été retrouvés dans l'urine du patient, mais jamais dans ses selles. Les PCR conventionnelles ont été réalisées à l'aide de paires d'amorces ciblant l'ADNr 28S et l'ADNmt (COI). L'analyse de la séquence de l'ADNr 28S de ces œufs, comparée à deux séquences de référence de GenBank a montré un hybride avec 25 doubles pics indiquant des positions clairement hybrides $(5,37 \%)$ entre $S$. mansoni et $S$. haematobium. De même, nous avons identifié une séquence COI unique pour les deux œufs, présentant une homologie de $99,1 \%$ avec la séquence de référence de $S$. mansoni. Par conséquent, ce cas est le résultat d'une hybridation entre un mâle $S$. haematobium et une femelle $S$. mansoni. Ce phénomène devrait être pris en compte pour explorer les éliminations atypiques d'œufs de bilharzies à l'avenir.

*Corresponding authors: jerome.depaquit@univ-reims.fr

This is an Open Access article distributed under the terms of the Creative Commons Attribution License (http://creativecommons.org/licenses/by/4.0), which permits unrestricted use, distribution, and reproduction in any medium, provided the original work is properly cited. 


\section{Introduction}

Schistosomiases are a group of neglected tropical diseases caused by dioecious trematode parasites of the genus Schistosoma. Based on a report of the World Health Organization (WHO), it is one of the most important tropical diseases, infecting more than 250 million people, mainly in sub-Saharan Africa [30].

The hybridization of closely related Schistosoma species has already been demonstrated in the laboratory [23], as well as in nature [8]. Nevertheless, hybridization between two major causative agents of intestinal and urinary schistosomiasis in Africa, Schistosoma mansoni and S. haematobium, has rarely been described [20] and was very recently observed in a patient originated from Côte d'Ivoire [19]. Hybridization between these two species is very surprising due to the high phylogenetic distance between them [15]. However, some cases of mixed infections have been reported in Mali [17], Senegal [24], and Kenya [11]. The elimination of ectopic S. mansoni eggs suggested possible hybridization between these two parasitic species, which were documented in humans in Cameroon [8], or in cercaria in Senegal [15].

In the present study, we report the case of a patient from Côte d'Ivoire, excreting living $S$. mansoni-like eggs in his urine without any excretion in his stools. This evidence, together with molecular characterization of some eggs, opens up a discussion on hybridization phenomenon between these genetically distant species. Although this case occurred 10 years ago, we decided to report it considering the invasiveness, frequency and persistence of schistosomiases caused by various hybrids [3, 4, 19, 27].

\section{Case report}

In March 2008, a 14-year-old schoolboy (weight: $45 \mathrm{~kg}$ ) who lived with his family in the suburbs of Paris, was referred by his doctor to the Parasitology-Mycology department of the Avicenne Hospital for hematuria and suspected urinary schistosomiasis. His parents are from Côte d'Ivoire, a country where he regularly went during school holidays. The last stay took place in the region of Divo (in south of the country) for 47 days from July 5 to August 20, 2007. The hematuria appeared one week after his return, without other symptoms. The 24-hour parasitological examination of urine performed on March 6, 2008, showed the presence of 35 eggs identified morphologically as $S$. mansoni. A total of 10 eggs were measured and their mean values were $150 \mu \mathrm{m}$ long $(156-146 \mu \mathrm{m}$, standard-error $3.20 \mu \mathrm{m}) / 62.5 \mu \mathrm{m}$ wide $(60-66 \mu \mathrm{m}$, standard-error $1.73 \mu \mathrm{m})$, and a $25 \mu \mathrm{m}$ lateral spin (23.5-27.5 $\mu \mathrm{m}$, standard-error $1.35 \mu \mathrm{m})$. These eggs contained mostly a living miracidium (Fig. 1). All the eggs exhibited the same shape. No terminal spined egg has been observed. Examination of stools performed on the same day found no parasite.

Based on this unusual result, the patient together with six members of his family were called again for urine and stool examinations on May 5, 2008. No parasites were found in the stools and urine of family members. Furthermore, no hematuria was observed among them. In contrast, about 30 S. mansoni eggs were found again in the patient's urine, but not in his stools.

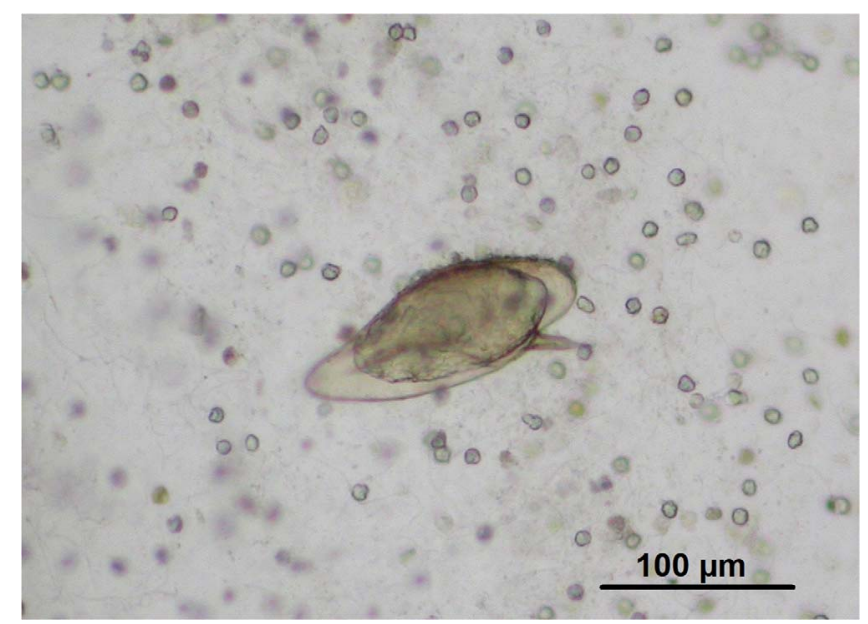

Figure 1. A hybrid S. mansoni/S. haematobium egg excreted in the urine of the patient.

Based on blood cell count, hypereosinophilia (1200 eosinophils $/ \mathrm{mm}^{3}$ ) was found in the patient's blood sample. In addition, no renal or urinary calcium opacity was observed, according to radiography of the abdomen without preparation. Echography examination showed localized bladder nodular thickening of $15 \mathrm{~mm}$. The patient was then treated orally with a single dose of three tablets of praziquantel $(1800 \mathrm{mg})$. The patient was examined again 18 months later. Urine and stool examinations were negative. The presence of living eggs located in the bladder plexus was confirmed by visualization of a bladder nodule on echography, which demonstrated active infestation in the urine.

\section{Materials and methods}

Urine and stool examinations for Schistosoma eggs were the primary methods, performed for diagnosis of suspected Schistosoma infections. For this purpose, a 24-hour urine sample of the patient was collected, decanted and the first infused drops were subjected to microscopic examination at $100 \times$ and $400 \times$ magnifications. Stool examination for eggs and parasites was carried out, using the merthiolate-iodineformaldehyde (MIF) stool concentration technique [1]. Furthermore, two single eggs were isolated, using a micropipette under a stereomicroscope. The eggs' DNA was extracted, using the Qiamp DNA Mini Kit (Qiagen, Germany). Conventional PCRs were performed, using $\mathrm{C} 2$ ' $\mathrm{b}$ and D2 primers for amplification of the D2 domain of 28S rDNA [25], and SchistoCox1-5' and SchistoCox $1-3^{\prime}$ primers for mtDNA COI amplification [35]. The latter is of maternal inheritance, which mainly supports DNA barcoding [13]. Amplicons were analyzed, using electrophoresis on $1.5 \%$ agarose gel, containing ethidium bromide. Moreover, amplicons were directly sequenced in both directions, using the same primers used for PCR.

Obtained sequences were edited by Staden package software, and compared with homologous sequences in GenBank, using the Basic Local Alignment Search Tool (BLAST) (www. ncbi.nlm.nih.gov/BLAST). Sequences were aligned with BioEdit v7.0.0 software [12]. Genetic distances and ML trees 
Table 1. Estimates of overall evolutionary divergence across sequence pairs including all nucleotides. The values in black are related to distances between Schistosoma species based on D2 sequences. The values in red are related to distances between Schistosoma species based on COI sequences. The COI intraspecific variability within $S$. mansoni excluding the hybrid processed in the present study is indicated in green.

\begin{tabular}{|c|c|c|c|c|c|c|c|c|c|}
\hline & S. mansoni & S. haematobium & S. bovis & S. curassoni & S. intercalatum & S. leiperi & S. margrebowiei & S. mattheei & S. rodhaini \\
\hline S. mansoni & 0.027 & 0.180 & 0.195 & 0.208 & 0.190 & 0.185 & 0.202 & 0.180 & 0.118 \\
\hline S. haematobium & 0.053 & & 0.114 & 0.117 & 0.113 & 0.098 & 0.14 & 0.142 & 0.152 \\
\hline S. bovis & 0.056 & 0.004 & & 0.058 & 0.120 & 0.120 & 0.140 & 0.131 & 0.167 \\
\hline S. curassoni & 0.058 & 0.006 & 0.002 & & 0.133 & 0.113 & 0.129 & 0.138 & 0.173 \\
\hline S. intercalatum & 0.056 & 0.004 & 0.000 & 0.002 & & 0.098 & 0.127 & 0.149 & 0.169 \\
\hline S. leiperi & 0.056 & 0.017 & 0.013 & 0.015 & 0.013 & & 0.138 & 0.140 & 0.151 \\
\hline S. margrebowiei & 0.060 & 0.026 & 0.024 & 0.026 & 0.024 & 0.028 & & 0.164 & 0.176 \\
\hline S. mattheei & 0.060 & 0.013 & 0.009 & 0.011 & 0.009 & 0.013 & 0.028 & & 0.158 \\
\hline S. rodhaini & 0.009 & 0.054 & 0.052 & 0.054 & 0.052 & 0.052 & 0.058 & 0.056 & \\
\hline
\end{tabular}

were obtained, using the HKY85 model on all codon sites, and MEGA7 software [18] was used for those containing gaps.

\section{Results}

Two fragments of 465 and 849 base pairs were amplified separately, using D2 and COI primer pairs, respectively, and visualized, using gel electrophoresis. Then, the sequences of these two egg samples were compared with those deposited in the GenBank.

Regarding the D2 fragment, there were 25 polymorphic position sites between $S$. mansoni (GenBank accession number AY157173) and S. haematobium (GenBank accession number AY157263). These reference sequences were selected because they were obtained from strains strongly identified and colonized under laboratory conditions. The D2 sequences from the two eggs showed 25 double peaks of equal intensity in the chromatogram at the same position of the referent sequences, clearly indicating hybrid positions between S. mansoni and S. haematobium

The D2 sequences included 25 double peaks of equal intensity, clearly indicating hybrid positions $(5.37 \%)$ between $S$. mansoni and S. haematobium.

The sequence of amplified mitochondrial marker (COI) was assessed, in order to explore the ascendance of this hybrid. We compared 849 bp of the COI sequence with those of $S$. mansoni and $S$. haematobium deposited in GenBank (accession numbers FN364013 and AY157209, respectively). We identified for the two eggs a unique S. mansoni COI sequence $(99.1 \%$ homology with the $S$. mansoni referent sequence FN364013). We analysed only $451 \mathrm{bp}$, in order to compare our sequence to 32 others deposited in GenBank, to calculate pairwise distances (Table 1) and build maximum likelihood trees.

The specimens we processed in the present study based on COI mtDNA sequences, are perfectly included in the $S$. mansoni branch (Fig. 2).

\section{Discussion}

Hybridization of parasites is an emerging public health concern worldwide. This phenomenon can have major impacts on

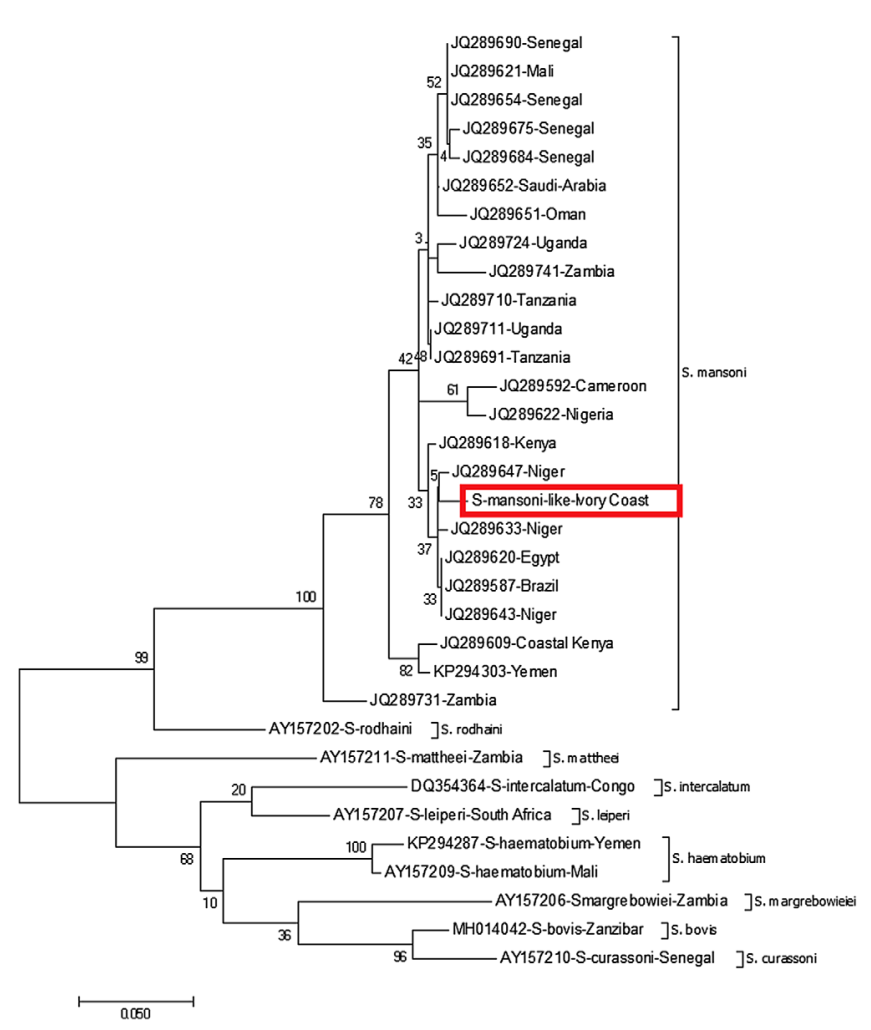

Figure 2. ML tree built on COI mtDNA sequences of Schistosoma spp. The percentage of trees in which the associated taxa clustered together is shown next to the branches. The tree is drawn to scale, with branch lengths measured in the number of substitutions per site.

the parasite-host relationship, as well as the epidemiology and course of disease. It can potentially lead to the evolution and emergence of new parasitic microorganisms and consequently new diseases $[9,16]$. The exchange of new genes may affect the pathogenicity and resistance of the parasites, and potentially complicates control measures [36]. For instance, S. haematobium is unable to develop solely in sheep [33], but its hybridization with $S$. mattheei simplifies the propagation in the mentioned host [32].

Hybridization is a frequent phenomenon between closely related species, such as among "Haematobium group" or between $S$. mansoni and $S$. rodhaini, but hybridization between 
S. mansoni and S. haematobium is reported very rarely, and is poorly documented. The eggs with lateral spins were first reported in the human bladder in 1884 by Sonsino [31], and then in 1886 by Belleli [2] who observed a purely $S$. mansoni bladder infection in Egypt. Since the 1900s, several authors have reported the presence of $S$. mansoni eggs in the urine $[6,10]$. More recently, the presence of this species was documented frequently in Africa [22, 34]. In 1991, Ratard and colleagues [28] observed patients excreting S. mansoni eggs in the urine in the north of Cameroon. A decade later, in agreement with Ratard's observation, a possible hybridization between $S$. haematobium and $S$. mansoni was strongly suspected in Cameroon [8], and proven in Senegal [15], whereas it has recently been observed in Côte d'Ivoire [19].

Based on comparison of the mitochondrial sequences of the hybrid specimens with those of S. mansoni (FN364013), the eggs excreted by the young boy seem to be the consequence of hybridization between a female $S$. mansoni and a male $S$. haematobium. However, it is impossible for us to predict if this child had already become infected by hybrid cercariae or if mating of the male $S$. haematobium and the female S. mansoni occurred in his body. A possible route for this hybridization is that the male transported the female to the usual location of S. haematobium. However, considering the multiple repeated cases of hybridization between the indicated species in Africa, this case should be taken into consideration in future microscopic and molecular identification of Schistosoma parasites.

Hybrids in Schistosoma are troublesome. They are well adapted to intermediate hosts in endemic foci of schistosomiasis, like in Senegal, where they seem to be able to modify the epidemiology of the disease [5, 29], maybe due to higher competitiveness. Moreover, they can spread and become invasive populations, like in Corsica, where a recent outbreak was the consequence of hybrids between $S$. haematobium and $S$. bovis [26]. The hybridization between $S$. haematobium and $S$. bovis is not surprising because they are two closely related species. Until recently, the hybridization host of the latter species remained enigmatic since these two species did not have the same final host; adults could not theoretically meet. However, it has recently been shown that small rodents could be their definitive hosts where this hybridization could occur [7]. For $S$. haematobium and $S$. mansoni, their genetic distance is greater, and consequently their hybridization more surprising, due to the significant phylogenetic distance [21, 37]. However, the chance of adults meeting is high because of the sympatry of both $S$. haematobium and $S$. mansoni and the high number of co-infections in some areas. To date, nothing is known about the possible intermediate hosts of such hybrids. S. haematobium exclusively infects Bulinus spp., whereas, Biomphalaria acts as an intermediate host for $S$. mansoni. The spread of these hybrids will be correlated to the distribution of their intermediate hosts. The use of new low-cost and high throughput tools like MALDI-TOF MS [14] to detect such hybrids could be helpful to explore this challenge.

Acknowledgements. The authors thank Damien Jouet for his technical help. The authors have no competing interests.

\section{References}

1. Allen A, Ridley D. 1970. Further observations on the formolether concentration technique for faecal parasites. Journal of Clinical Pathology, 23, 545-546.

2. Belleli V. 1886. La Bilharzia haematobia. Osservazioni an atomopathologiche e cliniche. Milan, Italy: Gazetta degli Ospitali.

3. Boissier J, Grech-Angelini S, Webster BL, Allienne JF, Huyse $\mathrm{T}$, Mas-Coma S, Toulza E, Barre-Cardi H, Rollinson D, Kincaid-Smith J, Oleaga A, Galinier R, Foata J, Rognon A, Berry A, Mouahid G, Henneron R, Mone H, Noel H, Mitta G. 2016. Outbreak of urogenital schistosomiasis in Corsica (France): an epidemiological case study. Lancet Infectious Diseases, 16(8), 971-979.

4. Boissier J, Mone H, Mitta G, Bargues MD, Molyneux D, Mas-Coma S. 2015. Schistosomiasis reaches Europe. Lancet Infectious Diseases, 15(7), 757-758.

5. Boon NAM, Van Den Broeck F, Faye D, Volckaert FAM, Mboup S, Polman K, Huyse T. 2018. Barcoding hybrids: heterogeneous distribution of Schistosoma haematobium $\mathrm{x}$ Schistosoma bovis hybrids across the Senegal River Basin. Parasitology, 145(5), 634-645.

6. Brayton N. 1910. Bilharziasis in the New World. Journal of American Association, 21, 1349-1440.

7. Catalano S, Sene M, Diouf ND, Fall CB, Borlase A, Leger E, Ba K, Webster JP. 2018. Rodents as natural hosts of zoonotic Schistosoma species and hybrids: an epidemiological and evolutionary perspective from West Africa. Journal of Infectious Diseases, 218(3), 429-433.

8. Cunin P, Tchuem Tchuenté L, Poste B, Djibrilla K, Martin P. 2003. Interactions between Schistosoma haematobium and Schistosoma mansoni in humans in north Cameroon. Tropical Medicine International Health, 8, 1110-1117.

9. Detwiler JT, Criscione CD. 2010. An infectious topic in reticulate evolution: introgression and hybridization in animal parasites. Genes (Basel), 1(1), 102-123.

10. Duncan A. 1903. Note on bilharzia. British Medical Journal, 1, 789-790.

11. Gouvras AN, Kariuki C, Koukounari A, Norton AJ, Lange CN, Ireri E, Fenwick A, Mkoji GM, Webster JP. 2013. The impact of single versus mixed Schistosoma haematobium and $S$. mansoni infections on morbidity profiles amongst schoolchildren in Taveta, Kenya. Acta Tropica, 128(2), 309-317.

12. Hall T. 1999. Bioedit: a user-friendly biological sequence alignment editor and analysis program for Windows 95/98/NT. Nucleic Acids Symposium Series, 4, 95-98.

13. Hebert P, Cywinska A, Ball S, de Waard J. 2003. Biological identifications through DNA barcodes. Proceedings of the Royal Society of London, B Biological Sciences, 270, 313-321.

14. Huguenin A, Depaquit J, Villena I, Ferté H. 2019. MALDI-TOF mass spectrometry: a new tool for the rapid identification of cercariae (Trematoda, Digenea). Parasite, 26, 11.

15. Huyse T, Van den Broeck F, Hellemans B, Volckaert FA, Polman K. 2013. Hybridisation between the two major African schistosome species of humans. International Journal for Parasitology, 43(8), 687-689.

16. King KC, Stelkens RB, Webster JP, Smith DF, Brockhurst MA. 2015. Hybridization in Parasites: Consequences for adaptive evolution, pathogenesis, and public health in a changing world. PLoS Pathogens, 11(9), e1005098.

17. Koukounari A, Donnelly CA, Sacko M, Keita AD, Landoure A, Dembele R, Bosque-Oliva E, Gabrielli AF, Gouvras A, Traore M, Fenwick A, Webster JP. 2010. The impact of single versus mixed schistosome species infections on liver, spleen and 
bladder morbidity within Malian children pre- and postpraziquantel treatment. BMC Infectious Diseases, 10, 227.

18. Kumar S, Stecher G, Tamura K. 2016. MEGA7: Molecular Evolutionary Genetics Analysis version 7.0 for bigger datasets. Molecular Biology and Evolution, 33(7), 1870-1874.

19. Le Govic Y, Kincaid-Smith J, Allienne JF, Rey O, de Gentile L, Boissier J. 2019. Schistosoma haematobium-Schistosoma mansoni hybrid parasite in migrant boy, France, 2017. Emerging Infectious Diseases, 25(2), 365-367.

20. Léger E, Webster JP. 2017. Hybridizations within the Genus Schistosoma: implications for evolution, epidemiology and control. Parasitology, 144(1), 65-80.

21. Lockyer AE, Olson PD, Ostergaard P, Rollinson D, Johnston DA, Attwood SW, Southgate VR, Horak P, Snyder SD, Le TH, Agatsuma T, McManus DP, Carmichael AC, Naem S, Littlewood DT. 2003. The phylogeny of the Schistosomatidae based on three genes with emphasis on the interrelationships of Schistosoma Weinland, 1858. Parasitology, 126(Pt 3), 203-224.

22. Luogbou Nzu D, Netongo Masumbe P, Bayemi P, Mbacham Fon W, Tchuem Tchuenté L. 2015. Detection of hybrid Schistosoma haematobium group species in Cameroon by PCR-RFLP of the second Internal Transcribed Spacer (ITS2). World Journal of Pharmaceutical Research, 4, 1961-1980.

23. Mansour NS, Soliman GN, El-Assal FM. 1984. Studies on experimental mixed infections of Schistosoma mansoni and $S$. haematobium in hamsters. Zeitschrift für Parasitenkunde, 70(3), 345-357.

24. Meurs L, Mbow M, Vereecken K, Menten J, Mboup S, Polman K. 2012. Epidemiology of mixed Schistosoma mansoni and Schistosoma haematobium infections in northern Senegal. International Journal for Parasitology, 42(3), 305-311.

25. Mollaret I, Jamieson BGM, Adlard RD, Hugall A, Lecointre G, Chombard C, Justine J-L. 1997. Phylogenetic analysis of the Monogenea and their relationships with Digenea and Eucestoda inferred from 28S rDNA sequences. Molecular and Biochemical Parasitology, 90(2), 433-438.

26. Moné H, Holtfreter MC, Allienne JF, Mintsa-Nguema R, Ibikounle M, Boissier J, Berry A, Mitta G, Richter J, Mouahid G. 2015. Introgressive hybridizations of Schistosoma haematobium by Schistosoma bovis at the origin of the first case report of schistosomiasis in Corsica (France, Europe). Parasitology Research, 114(11), 4127-4133.

27. Ramalli L, Mulero S, Noel H, Chiappini JD, Vincent J, BarreCardi H, Malfait P, Normand G, Busato F, Gendrin V, Allienne JF, Fillaux J, Boissier J, Berry A. 2018. Persistence of schistosomal transmission linked to the Cavu river in southern Corsica since 2013. Euro Surveillance, 23(4):pii=18-00017.

28. Ratard RC, Ndamkou CN, Kouemeni LE, Ekani Bessala MM. 1991. Schistosoma mansoni eggs in urine. Journal of Tropical Medicine and Hygiene, 94(5), 348-351.

29. Sène-Wade M, Marchand B, Rollinson D, Webster BL. 2018. Urogenital schistosomiasis and hybridization between Schistosoma haematobium and Schistosoma bovis in adults living in Richard-Toll, Senegal. Parasitology, 145(13), 1723-1726.

30. Siqueira LDP, Fontes DAF, Aguilera CSB, Timoteo TRR, Angelos MA, Silva L, de Melo CG, Rolim LA, da Silva RMF, Neto PJR. 2017. Schistosomiasis: Drugs used and treatment strategies. Acta Tropica, 176, 179-187.

31. Sonsino P. 1884. Ricerche sullo sviluppo della Bilharzia haematobia. Giornale della R. Accademia di Torino, 32, 17-21.

32. Tchuem Tchuente LA, Southgate VR, Njiokou F, Njine T, Kouemeni LE, Jourdane J. 1997. The evolution of schistosomiasis at Loum, Cameroon: replacement of Schistosoma intercalatum by $S$. haematobium through introgressive hybridization. Transactions of the Royal Society of Tropical Medicine and Hygiene, 91(6), 664-665.

33. Vercruysse J, Southgate V, Rollinson D. 1984. Schistosoma curassoni Brumpt, 1931 in sheep and goats in Senegal. Journal of Natural History, 18, 969-976.

34. Webster BL, Diaw OT, Seye MM, Webster JP, Rollinson D. 2013. Introgressive hybridization of Schistosoma haematobium group species in Senegal: species barrier break down between ruminant and human schistosomes. PLoS Neglected Tropical Diseases, 7(4), e2110.

35. Webster BL, Rudolfova J, Horak P, Littlewood DT. 2007. The complete mitochondrial genome of the bird schistosome Trichobilharzia regenti (Platyhelminthes: Digenea), causative agent of cercarial dermatitis. Journal of Parasitology, 93(3), 553-561.

36. Wright CA, Ross GC. 1980. Hybrids between Schistosoma haematobium and $S$. mattheei and their identification by isoelectric focusing of enzymes. Transactions of the Royal Society of Tropical Medicine and Hygiene, 74(3), 326-332.

37. Young ND, Jex AR, Li B, Liu S, Yang L, Xiong Z, Li Y, Cantacessi C, Hall RS, Xu X, Chen F, Wu X, Zerlotini A, Oliveira G, Hofmann A, Zhang G, Fang X, Kang Y, Campbell BE, Loukas A, Ranganathan S, Rollinson D, Rinaldi G, Brindley PJ, Yang H, Wang J, Wang J, Gasser RB. 2012. Whole-genome sequence of Schistosoma haematobium. Nature Genetics, 44(2), 221-225.

Cite this article as: Depaquit J, Akhoundi M, Haouchine D, Mantelet S \& Izri A. 2019. No limit in interspecific hybridization in schistosomes: observation from a case report. Parasite 26, 10.

\section{PARASTE}

An international open-access, peer-reviewed, online journal publishing high quality papers on all aspects of human and animal parasitology

Reviews, articles and short notes may be submitted. Fields include, but are not limited to: general, medical and veterinary parasitology; morphology, including ultrastructure; parasite systematics, including entomology, acarology, helminthology and protistology, and molecular analyses; molecular biology and biochemistry; immunology of parasitic diseases; host-parasite relationships; ecology and life history of parasites; epidemiology; therapeutics; new diagnostic tools.

All papers in Parasite are published in English. Manuscripts should have a broad interest and must not have been published or submitted elsewhere. No limit is imposed on the length of manuscripts.

Parasite (open-access) continues Parasite (print and online editions, 1994-2012) and Annales de Parasitologie Humaine et Comparée (1923-1993) and is the official journal of the Société Française de Parasitologie. 